\title{
Advance Care Planning in Nursing Homes and Assisted Living Communities
}

\author{
Timothy P. Daaleman, DO, MPH, \\ Department of Family Medicine, Cecil G. Sheps Center for Health Services Research, University of \\ North Carolina at Chapel Hill
}

Christianna S. Williams, PhD, Cecil G. Sheps Center for Health Services Research, University of North Carolina at Chapel Hill

John S. Preisser, PhD, Department of Biostatistics, School of Public Health, University of North Carolina at Chapel Hill

Philip D. Sloane, MD, MPH, Department of Family Medicine, Cecil G. Sheps Center for Health Services Research, University of North Carolina at Chapel Hill

Holly Biola, MD, MPH, and

Division of Geriatrics, Duke University Medical Center

Sheryl Zimmerman, PhD

School of Social Work, Cecil G. Sheps Center for Health Services Research, University of North Carolina at Chapel Hill

\begin{abstract}
Objectives-To determine the prevalence and characteristics of advance care planning (ACP) among persons dying in long-term care (LTC) facilities, and to examine the relationship between respondent, facility, decedent, and family characteristics and ACP.
\end{abstract}

Design-After-death interviews of family members of decedents and facility liaisons where decedents received care.

Setting-Stratified sample of 164 residential care/assisted living facilities and nursing homes in Florida, Maryland, New Jersey, and North Carolina.

Subjects-Family members and facility liaisons who gave 446 and 1014 reports, respectively, on 1015 decedent residents.

Measurements-Reports of death/dying discussions, known treatment preferences, and reports and records of signed living wills ( $\mathrm{LW}$ ), health care powers of attorney (HCPOA), do-not-resuscitate orders, and do-not-hospitalize orders.

(C) 2008 American Medical Directors Association. Published by Elsevier Inc. All rights reserved.

Corresponding Author: Timothy P. Daaleman, DO, MPH, Department of Family Medicine, University of North Carolina at Chapel Hill, Campus Box 7595, Manning Drive, Chapel Hill, NC 27599-7595, Phone: (919) 966-3889, Fax: (919) 966-6125, Email:E-mail: tim_daaleman@med.unc.edu.

Publisher's Disclaimer: This is a PDF file of an unedited manuscript that has been accepted for publication. As a service to our customers we are providing this early version of the manuscript. The manuscript will undergo copyediting, typesetting, and review of the resulting proof before it is published in its final citable form. Please note that during the production process errors may be discovered which could affect the content, and all legal disclaimers that apply to the journal pertain.

CONFLICTS OF INTEREST None 
Results-Family respondents reported a higher prevalence, compared with facility reports, of HCPOAs (92\% vs $49 \%$ ) and LWs ( $84 \%$ vs $43 \%$ ). In family reports, non-white race and no private insurance were significantly associated with lower prevalence of LWs and HCPOAs; additionally, residing in nursing homes (vs assisted living facilities) and in North Carolina were associated with lower prevalence of reported LWs. In facility reports, non-white race, unexpected death and residing in North Carolina or Maryland were significantly associated with lower prevalence of LWs, whereas high Medicaid case mix, intact cognitive status and high family involvement were associated with lower prevalence of HCPOAs. Concordance of family and facility reporting of HCPOAs was significantly greater in facilities with fewer than 120 beds.

Conclusions-The prevalence of ACP in LTC is much higher than previously described, and there is marked variation in characteristics associated with ACP, despite moderately high concordance, when reported by the facility or family caregivers.

\section{Keywords}

Advance care planning; end-of-life care; long-term care; nursing home; assisted living

\section{INTRODUCTION}

Advance care planning (ACP) - the process of reflection, discussion, and communication of treatment preferences among dying patients, family members, and care providers - has been advocated as a primary goal of quality end-of-life care. ${ }^{1-3}$ ACP involves an active interchange among stakeholders that occurs predominantly within healthcare settings when individual values are considered and communicated in light of treatment options. ${ }^{2}, 4$ As a result, ACP is often focused on the documentation of decision-making in the form of advance directives (ADs) within institutional contexts, such as hospitals 5,6 and nursing homes. ${ }^{7-14}$

Long-term care (LTC) facilities are becoming more frequent settings where patients live their final weeks and experience death; in fact, the proportion of deaths occurring in nursing homes is expected to double over the next 20 years. ${ }^{15}$ Epidemiologic studies report that $25 \%$ of deaths in older adults occur in nursing homes $(\mathrm{NHs}){ }^{16}$ and that two-thirds of $\mathrm{NH}$ residents remain in a LTC facility until their death, rather than being transferred to the hospital. ${ }^{17}$ These studies also report that annual mortality rates for residents of residential care/assisted living (RC/AL) facilities (i.e., those that provide room, board, assistance with activities of daily living and protective oversight) range from $16 \%$ to $22 \% .16$

Ideally, ACP within LTC facilities should be individualized for each resident. Further, cognitively unimpaired residents, family members, and staff should be well-informed and concordant in their understanding about decisions made about treatment options. ${ }^{3}, 13,18$ Unfortunately, this is not always the case. Prior research that has examined the prevalence and factors associated with advance directives in NHs has utilized administrative datasets, ${ }^{7-10}$ chart abstractions of $\mathrm{NH}$ records, ${ }^{11-14}$ and interviews with facility staff or resident proxies. 13, 14 For example, an analysis using the 1993 Minimum Data Set reported a 17\% prevalence of do-not-resuscitate orders (DNRs) ${ }^{7}$ while a chart review of $\mathrm{NH}$ records from 10 states in the same period documented a DNR prevalence of $31 \% .{ }^{12}$ It could be that heterogeneity in data sources and outcome measures contributes to wide variation in the reported prevalence of ADs within NHs, but other factors may be operative as well. ${ }^{19}$ Earlier studies of ACP have also been restricted to $\mathrm{NH}$ settings, which limits understanding of other long-term care venues such as assisted living. No prior study has examined characteristics that relate to the concordance of ACP reporting by family members and LTC staff, which would be helpful to understand in instances when conflict occurs. 
As part of a study of end-of-life care experiences in RC/AL facilities and NHs in four states, we sought to describe, compare, and evaluate the structure and process of end-of-life care for residents who died in, or were transferred up to three days before their death from LTC facilities. After-death interviews with family members of decedents and their staff caregivers from a stratified sample of 164 LTC facilities were used to address the following study aims: (1) to determine the prevalence of ACP in LTC; (2) to examine the relationship between resident, family, and facility characteristics and ACP among dying residents in LTC facilities, and; (3) to identify factors that relate to the concordance of facility and family reports of ACP.

\section{METHODS}

\section{Identification and Recruitment of Study Facilities and Subjects}

A total of $230 \mathrm{RC} / \mathrm{AL}$ facilities and NHs from four states (Florida, Maryland, New Jersey, North Carolina) participating in the Collaborative Studies of Long-Term Care (CS-LTC) agreed to identify decedents for this project. Sample facilities included NHs and three types of RC/AL facilities: (1) facilities with fewer than 16 beds; (2) larger "new-model" facilities, tending to have nursing support available and private accommodations; and (3) larger "traditional" facilities that do not meet the "new-model" definition established in previous work. ${ }^{20}$ Details and an overview of the CS-LTC typology are described elsewhere. ${ }^{21}$

At the time of facility recruitment, a facility liaison (the administrator, care supervisor or a designee) was identified and later contacted monthly by telephone to determine if any residents had died in the preceding 30 days. To be eligible, residents had to have died in a participating CS-LTC facility, or within three days of leaving the facility by transfer or discharge. Since we were examining end-of-life care in LTC, resident deaths were eligible only for those who had been living in the facility for at least 15 days in the last month of life. If the decedent was eligible, the facility liaison was asked to provide the name and contact information of a family member or responsible party who was most familiar with the decedent's care in the last month of life.

\section{Data Collection}

Once eligibility was determined, the liaison provided information about the AD on file. Also, a condolence letter and consent form introducing the study was mailed four weeks after the date of death to the deceased resident's identified family member. Interviewers followed up at least six weeks after the date of death to obtain verbal consent and conduct a telephone interview with family members; interviews lasted 45 to 90 minutes. A staff caregiver also provided data, and facility-level data were collected via telephone interviews with facility administrators. Reports were obtained on 1,015 decedent residents from 164 facilities. Facility reports were obtained for 1,014 of the decedents, and family reports were obtained from 446 families of decedents. In all, $31 \mathrm{NHs}, 62 \mathrm{RC} / \mathrm{AL}$ facilities ( $<16$ beds), 23 traditional RC/AL facilities, and 48 new-model RC/AL facilities participated. The study was reviewed and approved by the Institutional Review Board of the University of North Carolina at Chapel Hill prior to its initiation.

\section{Study Measures}

The facility liaison reported demographic information about the decedent resident, (including gender, race, age and length of stay) as well as whether the decedent had ADs known to the facility. Family respondents provided demographic information about themselves and their relationship to the decedent. They also reported their level of involvement with the resident's care and if the death was expected or not, as well as the resident's insurance status. A resident was considered cognitively impaired if staff or family respondents reported any one of the following: a) that, 1 or 3 months prior to death, the decedent was an "Alzheimer's type 
resident," in other words with significant memory problems, confusion, and difficulty making decisions or communicating, or had a related disease or another dementia; b) that the decedent was unable to speak or write in a meaningful way during the last month of life; or c) that the decedent was unconscious during all of the last month of life. If the staff report was unavailable, the determination was based on the same information reported by the family respondent.

Family members were presented with the following items related to ACP: (1) before he/she was near death, did you ever discuss issues or express ideas about death or dying with him/ her?; (2) did [resident] have a durable power of attorney for health care decisions, that assigned someone else the legal power to make decisions about his/her health care if he/she could not speak for himself/herself?; (3) did [resident] have a signed document about end-of-life care, like a living will, giving directions for the kind of medical treatment he/she would want if he/ she could not speak for himself/herself?, and; (4) to what extent did you know the kinds of medical treatment he/she preferred?

Facility liaisons reported facility organizational characteristics (e.g., bed size, proprietary status, case-mix) and whether each of the following advance directives was on file: (1) a living will (LW) that was signed by the resident; (2) a Do-Not-Resuscitate (DNR) order that was signed by a physician; (3) a Do-Not-Hospitalize (DNH) order that was signed by a physician, and; (4) a health care power of attorney (HCPOA) that was signed by the resident (which is sometimes referred to as a durable power of attorney for health care[DPOAHC]).

\section{Data Analysis}

We determined the prevalence of various forms of ACP by simple descriptive statistics, using both sources of information - the facility liaison and the family member. To evaluate whether the decedent sample for whom family ACP information was available ( $\mathrm{N}=445$; note one decedent is excluded who did not have a facility report) was a biased sample of all the decedents for whom a facility report was available $(\mathrm{N}=1,014)$, we used a logistic regression model with presence/absence of family data as the dependent variable and facility report of specified advance directive (yes/no) as the independent variable, controlling for facility type and profit status and decedent age, race and gender and accounting for within-facility clustering using Generalized Estimating Equations (GEE) ${ }^{22}$ and specifying an exchangeable correlation.

To simultaneously identify individual and facility characteristics that were associated with having a LW or HCPOA, as well as characteristics associated with concordance between family and facility report, we used an implementation of GEE known as alternating logistic regressions. ${ }^{23}$ This procedure provided fits of three models, logistic regressions for family and facility reports, and a model for the concordance between facility and family report using the pair-wise odds ratio (POR). The POR has the same interpretation as the usual odds ratio: given that a facility reports the existence of a particular advance directive (AD), what are the odds that the family member also reports the same $\mathrm{AD}$, relative to the odds of a family member reporting the $\mathrm{AD}$, given the facility report of no $\mathrm{AD}$. The POR between facility and family report can be computed from a $2 \times 2$ table constructed using data from residents having both reports. However, due to intra-cluster correlation within LTC facilities, we used alternating logistic regression in order to obtain correct standard errors for the PORs (on the log scale) leading to confidence intervals for PORs (on the untransformed scale) that appropriately account for clustering. All analyses were conducted using SAS software (version 9.1, SAS Institute, Cary, NC).

\section{RESULTS}

Over 3,106 facility-months of death ascertainment, 1,484 deaths were identified and of these deaths, 1,020 (68.7\%) were eligible. Of the 464 excluded decedents, 319 had been out of the 
facility more than 3 days and the remaining 145 had not been in the facility at least 15 days in the last month of life. Data on ACP documentation from the facility liaison were available for $1,014(99.4 \%)$ of the eligible decedents from 164 facilities. Between July 2002 and January 2005 we completed interviews with 451 family members of decedents (44\% of eligible decedents, $68 \%$ of those for whom we were able to identify and contact an eligible family member). ACP data were provided by family respondents for $446(98.9 \%)$ of these decedents, representing 127 facilities.

Table 1 contains characteristics of the facilities, decedents, and family respondents who participated in the study. Most facilities were for-profit (81\%), had high resident occupancy (average $83 \%$ ), and reported at least weekly visits by medical care providers (67\%); however only $26 \%$ of RC/AL facilities had an RN/LPN available on site. The demographic characteristics of the decedents included an average age of 85 years; most were female $(71 \%)$, white $(88 \%)$, and cognitively impaired (77\%). Resident death had been expected by about half $(53 \%)$ of reporting family members. Family respondents were predominantly children of decedents $(67 \%)$, and the majority reported their involvement with the decedent during the last month of life as either high $(26 \%)$ or very high $(52 \%)$.

Table 2 presents the prevalence of various forms of ACP as reported by either the facility or the family respondent. The table compares the prevalence of each type of ACP for decedents with and without family respondent information. Family respondents reported a high prevalence of HCPOAs (92\%), known treatment preferences $(91 \%)$, and signed LWs (84\%). Facilities, however, reported a much lower prevalence of signed HCPOAs (49\%) and LWs $(43 \%)$. We found no difference when comparing the prevalence of facility-reported LWs, DNR, and DNH orders, however the prevalence of HCPOAs was higher for those with family information compared to those without $(54 \%$ vs. $45 \%, \mathrm{p}=0.013)$.

Table 3 displays the association of facility, decedent, and family characteristics with the resident having a LW, and the within decedent concordance of family and facility reporting. Per the family report, facilities that were NHs and those located in North Carolina were associated with a lower prevalence of LWs. Facilities that were located in North Carolina and Maryland were also associated with a lower prevalence of LWs according to the facility report. Non-white race and having no private insurance were decedent characteristics associated with a lower prevalence of LWs, per the family report. Per facility reporting, non-white race and a death that was not expected were associated with lower LW prevalence. Family members were much more likely to report that the resident had a LW than were facility staff (OR $=6.46,95 \%$ $\mathrm{CI}=4.67,8.93 ; \mathrm{p}<0.001)$. Although we found statistically significant concordance between family and facility reporting of $\mathrm{LWs}(\mathrm{POR}=5.53,95 \% \mathrm{CI}=2.31,13.19 ; \mathrm{p}<0.001)$, we found no resident, facility, or family characteristics that were associated with such concordance.

Table 4 presents the association of facility, decedent, and family characteristics with the resident having a HCPOA and the within decedent concordance of family and facility reporting. While no facility characteristics were significantly associated with having a HCPOA as per family report, two were marginally significant: nursing home residence $(\mathrm{p}=0.058)$ and being in North Carolina ( $\mathrm{p}=0.079$ ); both of which were associated with lower use. Facilities that had a high Medicaid case mix were associated with a lower prevalence of HCPOAs, per the facility report. According to family report, non-white race and having no private insurance were decedent characteristics associated with lower HCPOA prevalence. Intact cognitive status and high family involvement were decedent characteristics associated with a lower prevalence of HCPOAs, per facility reporting. Family members were much more likely to report that the resident had a HCPOA than were facility staff $(\mathrm{OR}=10.55,95 \% \mathrm{CI}=7.00,15.90 ; \mathrm{p}<0.01)$. Overall, we found statistically significant concordance between family and facility reporting of HCPOAs $(\mathrm{POR}=3.81,95 \% \mathrm{CI}=1.41,10.25 ; \mathrm{p}<0.01)$. Concordance of family and facility 
reporting of HCPOAs was significantly greater in facilities with fewer than 120 beds, compared to larger facilities $(\mathrm{p}=0.042)$.

\section{DISCUSSION}

Long-term care facilities are playing an increasingly prominent role in end-of-life care. ${ }^{24}$ To provide the highest quality care in these settings, LTC stakeholders need an understanding of the individual and organizational factors that relate to the ACP processes of reflection, discussion, and communication of treatment preferences among dying patients, family members, and care providers. ${ }^{24}$ To our knowledge, this study is the first to comprehensively describe the prevalence of, and factors associated with, ACP across a range of LTC facilities that includes RC/AL settings. We found that the prevalence of all measures of ACP was much higher than previously reported; Table 5 presents our data comparatively with prior studies.

There are two interpretations for the rise in ACP prevalence. First, since passage of the Patient Self Determination Act in 1990 there has been increased awareness in improving the documentation of ADs, especially in NHs. ${ }^{25}$ Table 5 demonstrates a progressively upward trend of ADs over time which may reflect a heightened regulatory attention to protecting residents' rights. ${ }^{26} \mathrm{~A}$ second interpretation considers how ACP is measured and estimated in LTC facilities. To begin, the wide variation in reported AD prevalence has been attributed to heterogeneity in both data sources and outcome measures. ${ }^{19}$ The reliance on administrative datasets, such as Medicare claims data ${ }^{8}$ and the Medical Expenditure Panel Survey, ${ }^{9}$ has been another limitation. Further, although prevalence estimates generally use all members of a population that are captured as the denominator, many of these members are not at high risk of death. ${ }^{27}$ Therefore, to estimate the prevalence of ACP in LTC facilities, the true "at risk" population would not include the total population of LTC residents, such as those undergoing a short rehabilitation, but only those most "at risk" of dying within the facility. We used decedents from LTC facilities as our denominator population at risk which provided a more accurate estimate of ACP for those who truly needed it.

The existing literature on ACP has focused largely on $\mathrm{NHs}^{7-14}$ and little data from RC/ALs have previously been reported. ${ }^{28}$ Our study, the first to include RC/AL facilities in examining this topic in depth, suggests that both resident and facility level factors relate to ACP across the spectrum of LTC. At the facility level, use in these settings was 5-10\% higher than NHs; also geographic location and facility type were associated with the prevalence of ADs in our study. The geographic variation in ADs previously described in the literature has been attributed to several factors: (1) the variation in available healthcare resources, such as hospital beds; (2) state laws regarding the documentation of care preferences; and (3) regional variation in protocols for care at the end of life. ${ }^{8,29}$ Although differences in state regulations have been proposed as a plausible, unifying theory to account for variation in ADs, no study has investigated the effect of state policies on AD completion. ${ }^{8}$

At the individual level, two resident factors, non-white race and having no private insurance, were associated with a lower prevalence of $\mathrm{ADs}$ in our study, which is consistent with prior work. ${ }^{8,} 30$ We also found that residents with intact cognitive status, who had high family involvement, and who had a death that was unexpected were less likely to have ADs. These data direct attention to factors that may contribute to the restricted communication and limited care planning discussions among care providers, residents with decisional capacity, and family members. ${ }^{31}$ Similarly, other studies found that nearly half of NH residents with DNR orders who could have participated in discussions about life-sustaining treatment report that they do not discuss these issues with their caregivers. ${ }^{11}$ In addition, most family caregivers of dying LTC residents receive little information about what to expect, and are not well informed from physicians. ${ }^{32}$ 
Poor communication among stakeholders may account for the striking variance in facility and family reporting of ACP found in Table 2. The increased prevalence of ACP reported by family respondents may reflect either lack of adequate communication between families and facility staff or, alternatively, their lack of understanding of the various AD documents, such as DNR and DNH orders. Concordance of family and facility reporting was greater in smaller facilities (i.e., $<120$ beds), when compared to larger facilities. However, although facility size may facilitate better communication among physicians, staff, and family members - and theoretically greater concordance -our prior work found no association between facility bed size and family member perceptions of physician communication at the end of life. ${ }^{32}$

There were several limitations to our study. First, the sample for which family data were available represented a relatively small percentage of decedents ( $44 \%$ of eligible decedents, $68 \%$ of those for whom we were able to identify and contact an eligible family member) and sample sizes for some of the analyses were small. Specifically, African Americans and families from nursing homes (vs RC/AL facilities) had a slightly higher refusal rate than others (12\% vs $7 \%$ for African Americans vs others; and 68\% vs 56\% for nursing homes vs RC/AL settings). Second, all individuals who died more than three days after transfer out of the LTC facility were excluded from study; the extent to which hospice use might have related to the resulting sample and ACP is unknown. Third, we used a retrospective design which introduces the possibility of recall bias.

The use of surrogate respondent reports raises some question regarding the validity of our primary outcome, ACP. There has been reported discordance between elderly patients and their surrogates regarding end-of-life care. ${ }^{33,} 34$ A systematic review, for example, found that surrogates predicted patients' preferences with $68 \%$ accuracy. ${ }^{35}$ Twelve studies assessed the type of surrogate error made: 3 studies found error due to providing undesired interventions, 1 study found error by withholding desired interventions, and; 8 studies found no trend regarding surrogate error. ${ }^{35}$ Therefore, while interviewing bereaved family members is a wellrecognized methodology in end-of-life care research, 36 further study examining the accuracy of such reporting would benefit the field. In addition, further study is needed to examine whether individuals understand the meaning of the form they have signed, as the limitations of such forms are not always clear. ${ }^{37}$ Finally, our interview was comprised primarily of closedended questions regarding ACP, which may have limited respondents in their understanding and description. On the other hand, the questionnaire provided a standardized way to capture a range of ACP outcomes.

\section{CONCLUSION}

In summary, we found that the prevalence of various types of ACP in LTC was much higher than previously reported; was 5-10\% higher in RC/AL than in nursing homes as per family report; that reported prevalence varied by state and by respondent status (facility staff or family caregiver); and that concordance of family and facility reporting of HCPOAs was greater in smaller (i.e., $<120$ beds) facilities. Future efforts to improve ACP should consider how these facility-level factors relate to an ongoing communication process of negotiating and formulating pathways of care for residents living in the light of death.

\section{ACKNOWLEDGEMENTS}

This study was supported by the National Institute on Aging (R01 AG13863, K02 AG00970, K23 AG001033) and the UNC Center for Aging and Health. The funding agencies had no role in the design and conduct of the study; collection, management, analysis, and interpretation of the data; and preparation, review, or approval of the manuscript. All authors had full access to all of the data in the study and take responsibility for the integrity of the data and the accuracy of the data analysis. We are very grateful to the staff, residents, and family members participating in the Collaborative Studies of Long-Term Care (CS-LTC) for their time and efforts. 


\section{Bibliography}

1. Miles SH, Koepp R, Weber EP. Advance end-of-life treatment planning. Archives of Internal Medicine 1996;156:1062-1068. [PubMed: 8638992]

2. Field, MJ.; Cassel, CK. Approaching Death. Washington, DC: National Academy Press; 1997.

3. Teno JM, Gruneir A, Schwartz A, Nanda A, Wetle T. Association between advance directives and quality end-of-life care: a national study. J Am Geriatr Soc 2007;55:189-194. [PubMed: 17302654]

4. Cantor MD, Pearlman RA. Advance care planning in long-term care facilities. Journal of the American Medical Directors Association 2004;5:S73-S80.

5. Teno JM, Lynn J, Wenger NS, et al. Advance directives for seriously ill hospitalized patients: effectiveness with the patient self-determination act and the SUPPORT intervention. J Am Geriatr Soc 1997;45:500-507. [PubMed: 9100721]

6. Zingmond DS, Wenger NS. Regional and institutional variation in the initiation of early do-notresuscitate orders. Archives of Internal Medicine 2005;165:1705-1712. [PubMed: 16087817]

7. Suri DN, Egleston BL, Brody JA, Rudberg MA. Nursing home resident use of care directives. Journals of Gerontology Series A: Biological Sciences and Medical Sciences 1999;54:M225-M229.

8. Levy CR, Fish R, Kramer A. Do-not-resuscitate and do-not-hospitalize directives of persons admitted to skilled nursing facilities under Medicare benefit. Journal of the American Geriatrics Society 2005;53:2060-2068. [PubMed: 16398888]

9. Dobalian A. Advance care planning documents in nursing facilities: results from a nationally representative survey. Archives of Gerontology and Geriatrics 2006;43:193-212. [PubMed: 16325939]

10. McAuley WJ, Travis SS. Advance care planning among residents in long-term care. American Journal of Hospice \& Palliative Care 2003;20:353-359. [PubMed: 14529038]

11. Levin JR, Wenger NS, Ouslander JG, et al. Life-sustaining treatment decisions for nursing home residents: who discusses, who decides, and what is decided? Journal of the American Geriatrics Society 1999;47:82-87. [PubMed: 9920234]

12. Teno JM, Branco KJ, Mor V, et al. Changes in advance care planning in nursing homes before and after the patient Self-Determination Act: report of a 10-year state survey. Journal of the American Geriatrics Society 1997;45:939-944. [PubMed: 9256845]

13. Happ MB, Capezuti E, Strumpf NE, et al. Advance care planning and end-of-life care for hospitalized nursing home residents. Journal of the American Geriatrics Society 2002;50:829-835. [PubMed: 12028168]

14. Allen RS, DeLaine SR, Chaplin WF, et al. Advance care planning in nursing homes: correlates of capacity and possession of advance directives. Gerontologist 2003;43:309-317. [PubMed: 12810894]

15. Brock DB, Foley DJ. Demography and epidemiology of dying in the US with emphasis on deaths of older persons. Hospice Journal 1998;13:49-60. [PubMed: 9644392]

16. Zimmerman S, Sloane PD, Eckert JK, et al. How good is assisted living? Findings and implications from an outcomes study. J Gerontol B Psychol Sci Soc Sci 2005;60:S195-S204. [PubMed: 15980295]

17. Kiely DK, Flacker JM. The protective effect of social engagement on 1-year mortality in a long-stay nursing home population. Journal of Clinical Epidemiology 2003;56:472-478. [PubMed: 12812822]

18. Gillick MR. Adapting advance medical planning for the nursing home. Journal of Palliative Medicine 2004;7:357-361. [PubMed: 15130217]

19. Cohen-Mansfield J, Libin A, Lipson S. Differences in presenting advance directives in the chart, in the Minimum Data Set, and through staff's perception. Gerontologist 2003;43:302-308. [PubMed: 12810893]

20. Zimmerman S, Gruber-Baldini AL, Sloane PD, Eckert JK, et al. Assisted living and nursing homes: apples and oranges? Gerontologist 2003;43:107-117. [PubMed: 12711731]

21. Zimmerman, S.; Sloane, PD.; Eckert, JK.; al, e. Overview of the collaborative studies of long-term care. In: Zimmerman, S.; Sloane, PD.; Eckert, JK., editors. Assisted living: needs, practices, and policies in residential care for the elderly. Baltimore, MD: Johns Hopkins University Press; 2001. 
22. Diggle, P.; Heagerty, P.; Liang, K-Y.; Zeger, S. The analysis of longitudinal data. Vol. 2nd ed.. Oxford: Oxford University Press; 2002.

23. Carey V, Zeger SL, Diggle P. Modeling multivariate binary data with alternating logistic regressions. Biometrika 1993;80:517-526.

24. Teno JM. Advance directives for nursing home residents. Journal of the American Medical Association 2000;283:1481-1482. [PubMed: 10732940]

25. Bradley E, Wetle T, Horwitz D. The Patient Self-Determination Act and advance directive completion in nursing homes. Archives of Family Medicine 1998;7:417-423. [PubMed: 9755733]

26. Code of Federal Regulations. Requirements for states and long term care facilities. US Government Printing Office. Available at: http://www.access.gpo.gov/nara/cfr/waisidx_01/42cfr483_01.html.

27. Katz JN, Losina E. Measures matter: racial disparities in the provision of total knee replacement. Arthritis \& Rheumatism 2005;53:805-807. [PubMed: 16342094]

28. Sloane PD, Zimmerman S, Hanson LC, et al. End-of-life care in assisted living and related residential care settings: comparison with nursing homes. J Am Geriatr Soc 2003;51:1587-1594. [PubMed: 14687388]

29. Dartmouth Medical School Center for the Evaluative Clinical Sciences. The care of patients with severe chronic illness. Dartmouth Medical School. Available at: www.dartmouthatlas.org.

30. Kiely DK, Mitchell SL, Marlow A, et al. Racial and state differences in the designation of advance directives in nursing home residents. J Am Geriatr Soc 2001;49:1346-1352. [PubMed: 11890494]

31. Shield RR, Wetle T, Teno JM, et al. Physicians 'missing in action': Patients' perspectives on physician and staffing problems in end-of-life care in the nursing home. J Am Geriatr Soc 2005;53:1651-1657. [PubMed: 16181162]

32. Biola H, Sloane PD, Williams CS, Daaleman TP, Williams SW, Zimmerman S. Physician Communication with Family Members of Long-term Care Residents at the End of Life. Journal of the American Geriatrics Society 2007;55:846-856. [PubMed: 17537084]

33. Ouslander JG, Tymchuk AJ, Rahbar B. Health care decisions among elderly long-term care residents and their potential proxies. Archives of Internal Medicine 1989;149:1367-1372. [PubMed: 2499292]

34. Gerety MB, Chiodo LK, Kanten DN, et al. Medical treatment preferences of nursing home residents: relationship to function and concordance with surrogate decision-makers. Journal of the American Geriatrics Society 1993;41:953-960. [PubMed: 8204138]

35. Shalowitz DI, Garrett-Mayer E, Wendler D. The accuracy of surrogate decision makers. Archives of Internal Medicine 2006;166:493-497. [PubMed: 16534034]

36. Hanson LC, Danis M, Garrett JM. What is wrong with end of life care? Journal of the American Geriatrics Society 1997;45:1339-1344. [PubMed: 9361659]

37. Hoffman DE, Zimmerman SI, Tompkins CJ. The dangers of directives or the false security of forms. Journal of Law and Medical Ethics 1996;24:5-17. 
Characteristics of the study sample

Table 1

\begin{tabular}{|c|c|c|}
\hline & $\mathbf{N}$ (Percent) & Mean (SD) \\
\hline \multicolumn{3}{|l|}{ Characteristics of Facilities $(\mathrm{n}=164)^{a}$} \\
\hline \multicolumn{3}{|l|}{ Facility } \\
\hline $\mathrm{RC} / \mathrm{AL}<16$ beds & $62(37.8)$ & \\
\hline Traditional RC/AL & $23(14.0)$ & \\
\hline New-Model RC/AL & $48(29.3)$ & \\
\hline Nursing Home & $31(18.9)$ & \\
\hline \multicolumn{3}{|l|}{ State } \\
\hline Florida & 49 (29.9) & \\
\hline Maryland & $45(27.4)$ & \\
\hline North Carolina & $41(25.0)$ & \\
\hline New Jersey & $29(17.7)$ & \\
\hline For-profit facility & $128(81.0)$ & \\
\hline Part of a chain & $88(57.1)$ & \\
\hline Bed size & & $53.2(45.3)$ \\
\hline Percent with Medicaid as primary payer & & $29.7(31.7)$ \\
\hline Occupancy percent & & $83.4(18.4)$ \\
\hline Staffing ratio (per 10 resident) ${ }^{b}$ & & $5.1(2.2)$ \\
\hline Aide ratio (per 10 resident $)^{b}$ & & $4.1(1.9)$ \\
\hline Visits by MD, PA, NP at least weekly & $99(66.9)$ & \\
\hline $\mathrm{RN} / \mathrm{LPN}$ on site ${ }^{c}$ & $30(25.6)$ & \\
\hline $\mathrm{RN} / \mathrm{LPN}$ on call $24 / 7^{c}$ & $74(63.2)$ & \\
\hline At least 1 FTE RN & $79(53.4)$ & \\
\hline \multicolumn{3}{|l|}{ Characteristics of Decedents $(\mathbf{n}=\mathbf{1 , 0 1 5})^{d}$} \\
\hline Age & & $85.1(9.5)$ \\
\hline Male gender & $297(29.3)$ & \\
\hline Nonwhite race & $121(11.9)$ & \\
\hline Length of stay (yrs) & & $2.2(2.6)$ \\
\hline Self-pay or commercial insurance ${ }^{e}$ & $403(92.4)$ & \\
\hline Cognitively intact ${ }^{e}$ & $181(23.1)$ & \\
\hline Number of ADL dependencies $(0-3)^{e}$ & & $1.6(1.2)$ \\
\hline Death was expected by family ${ }^{e}$ & $236(52.8)$ & \\
\hline \multicolumn{3}{|c|}{ Characteristics of Family Respondents $(\mathrm{n}=\mathbf{4 4 6})^{f}$} \\
\hline \multicolumn{3}{|l|}{ Relationship to decedent } \\
\hline Spouse & $38(8.5)$ & \\
\hline Child & $299(67.0)$ & \\
\hline Other relative & $80(17.9)$ & \\
\hline Other & $29(6.5)$ & \\
\hline Age & & $60.4(11.5)$ \\
\hline College graduate & $216(49.0)$ & \\
\hline Days visited resident in last month & & $15.3(10.4)$ \\
\hline
\end{tabular}




\begin{tabular}{|c|c|c|}
\hline & $\mathbf{N}$ (Percent) & Mean (SD) \\
\hline \multicolumn{3}{|l|}{ Self-reported involvement } \\
\hline Moderate, low, or very low & $97(22.1)$ & \\
\hline High & $115(26.3)$ & \\
\hline Very high & $226(51.6)$ & \\
\hline \multicolumn{3}{|c|}{$\begin{array}{l}\text { a Sample includes all facilities with at least one eligible decedent for which the facility provided information about advance directives. Sample size fo } \\
\text { specific variables ranges from } 146 \text { to } 164 \text { because of missing data on some items. }\end{array}$} \\
\hline \multicolumn{3}{|c|}{$\begin{array}{l}b \text { Staffing ratio includes RNs, LPNs and aides (\# full time + } 1 / 2 \text { part-time for each) per } 10 \text { residents; aide ratio is \# full time + } 1 / 2 \text { part-time aides per } 10 \\
\text { residents. }\end{array}$} \\
\hline \multicolumn{3}{|c|}{${ }^{c} \mathrm{RC} / \mathrm{AL}$ only ( $\mathrm{N}=117$ with data on these items). } \\
\hline \multicolumn{3}{|c|}{$d_{\text {Includes all eligible decedents for which the facility or the family provided information about advance directives. }}$} \\
\hline \multicolumn{3}{|c|}{$\begin{array}{l}\text { e Insurance information and expectation of death obtained on family interview, available for } 436 \text { and } 447 \text { decedents respectively; cognitive status } \\
\text { information obtained from staff or family interview, available for } 785 \text { decedents; ADL status obtained on staff interview, available for } 664 \text { decedents }\end{array}$} \\
\hline
\end{tabular}




\section{Table 2}

Prevalence of advance care planning among long-term care residents

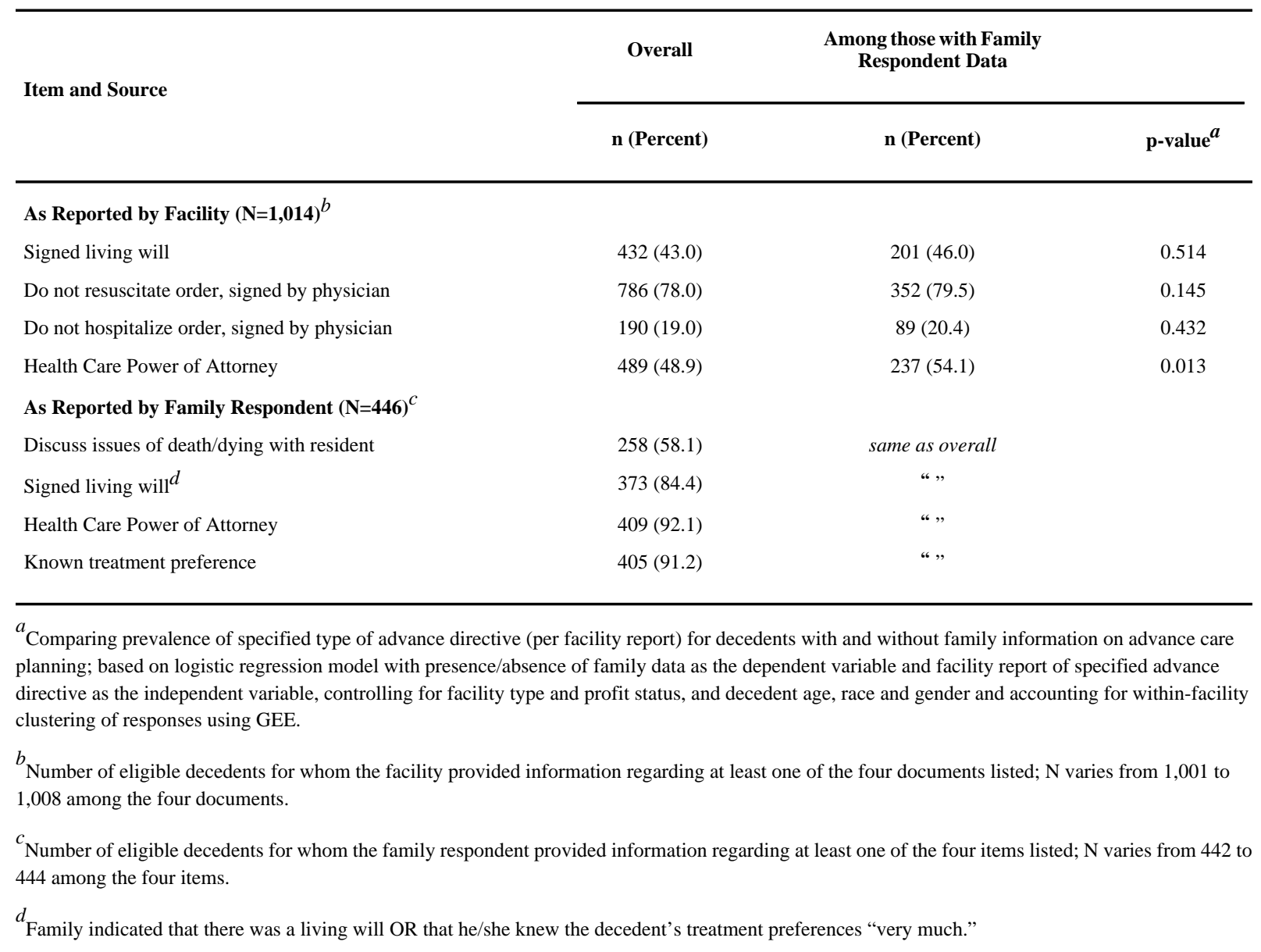


:

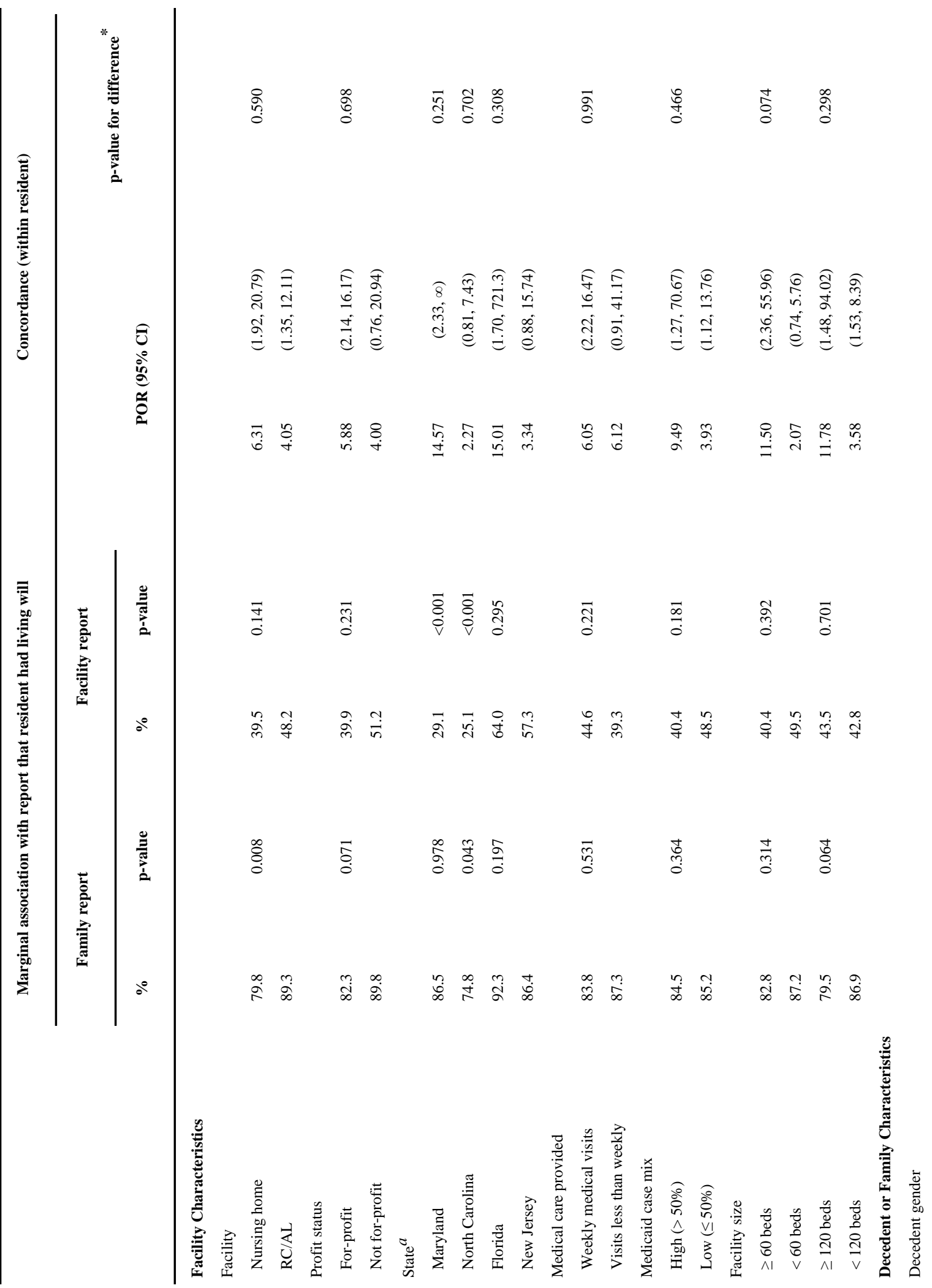

J Am Med Dir Assoc. Author manuscript; available in PMC 2010 May 1. 


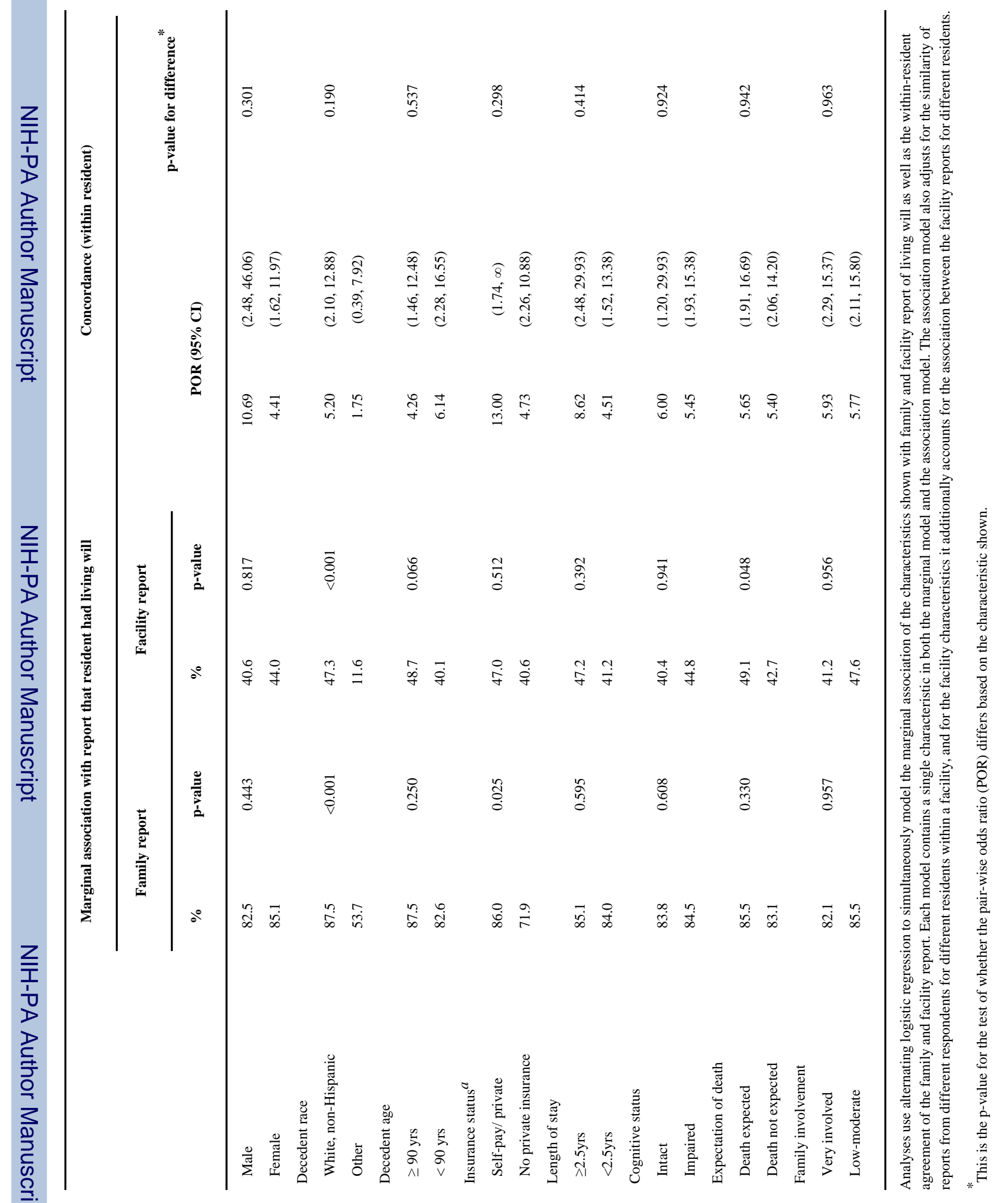




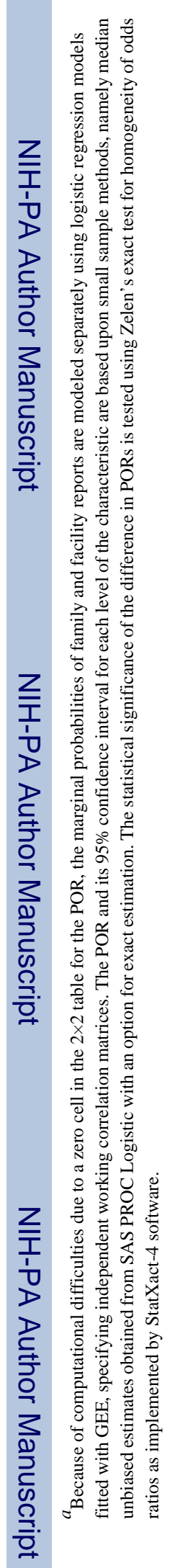

J Am Med Dir Assoc. Author manuscript; available in PMC 2010 May 1. 


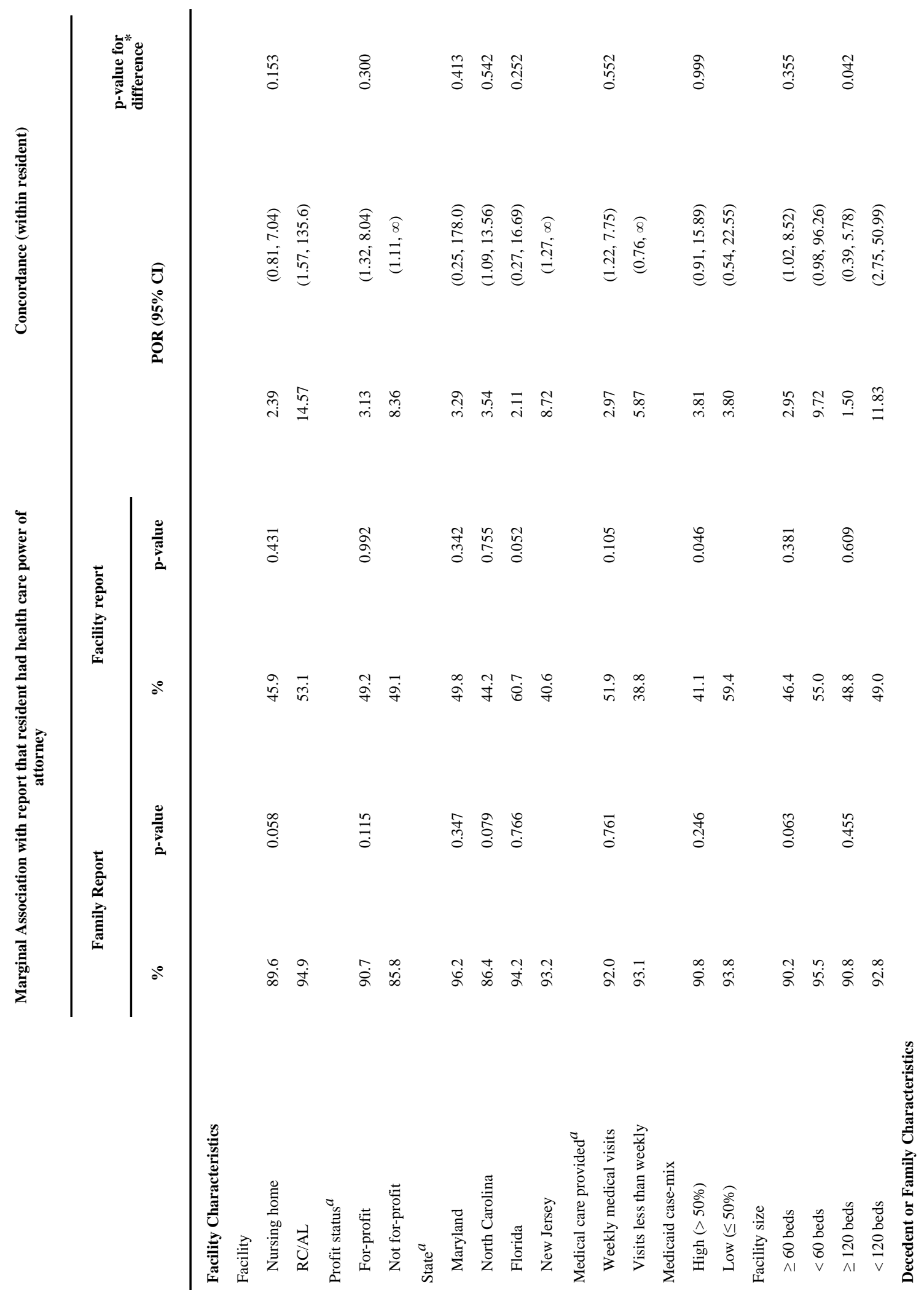




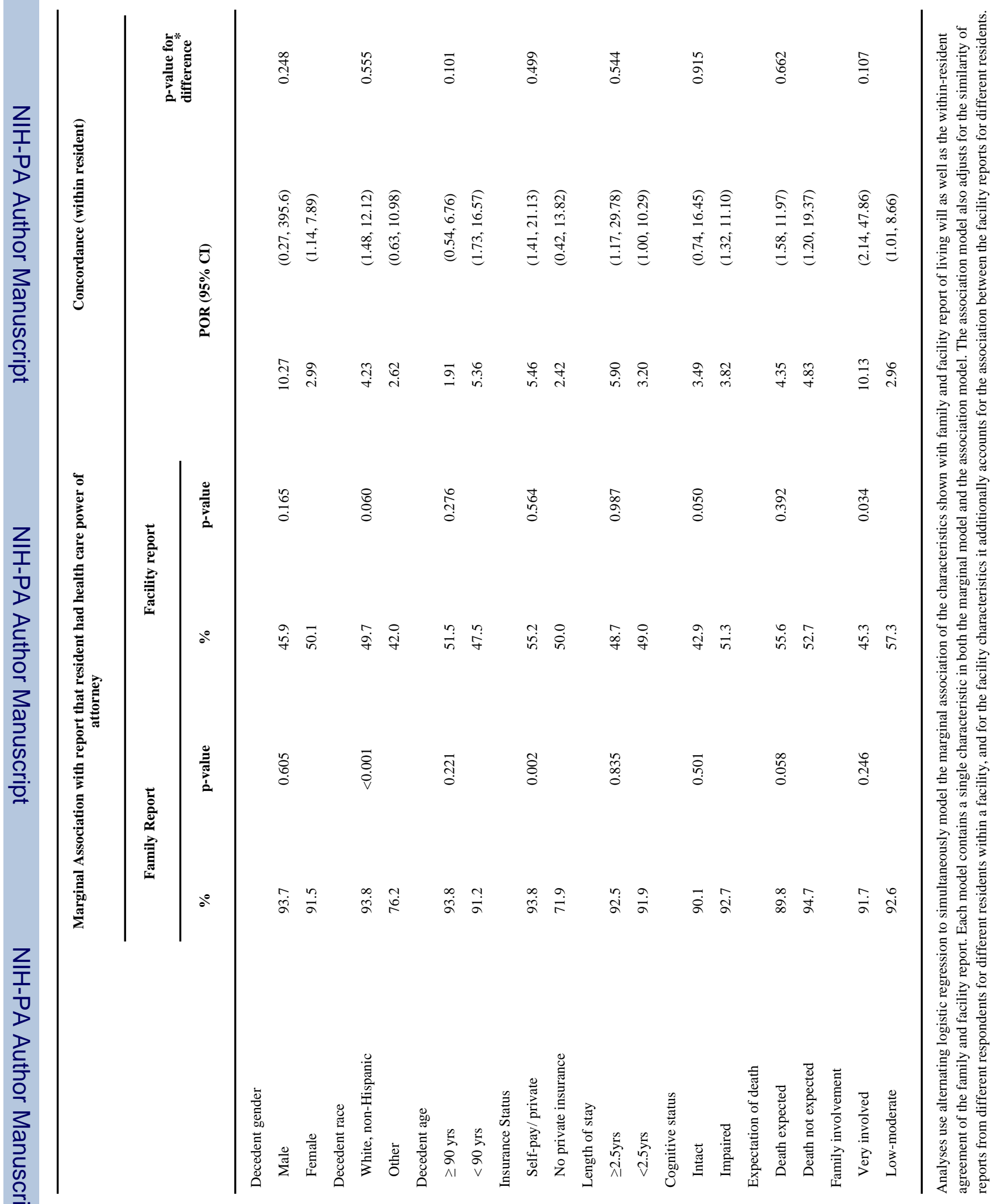




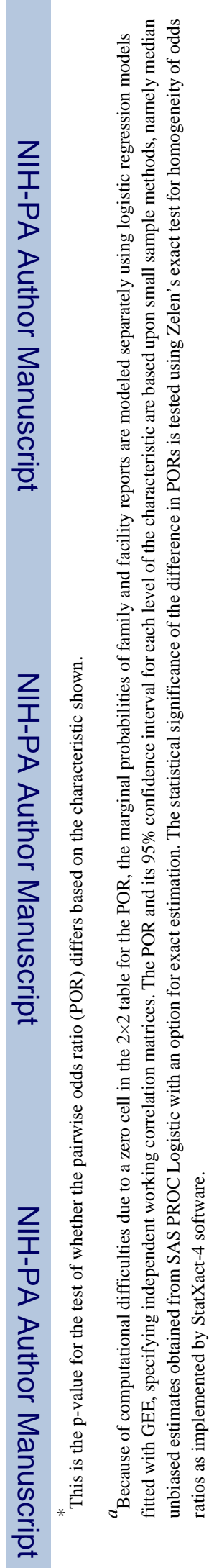

J Am Med Dir Assoc. Author manuscript; available in PMC 2010 May 1. 


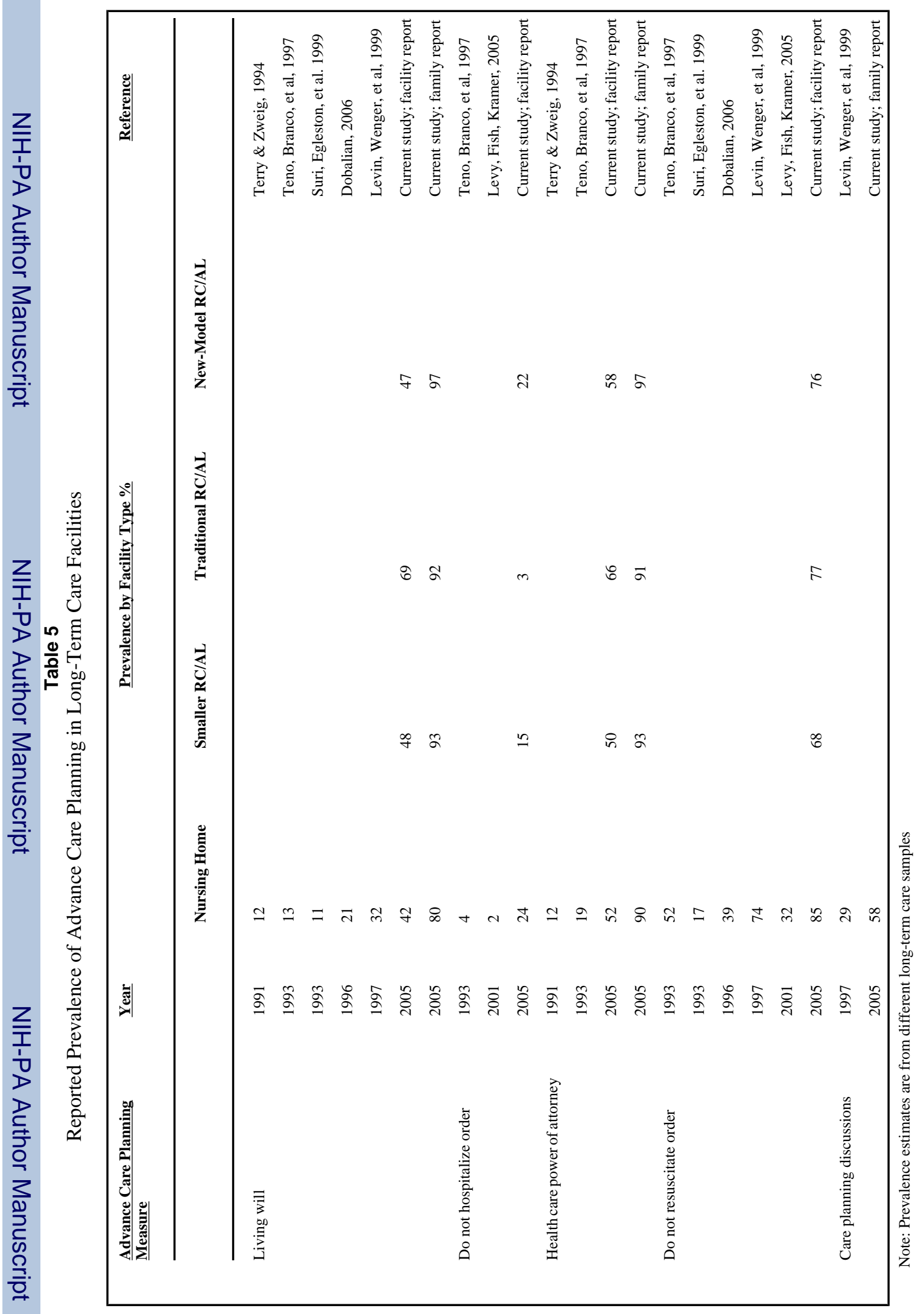

J Am Med Dir Assoc. Author manuscript; available in PMC 2010 May 1. 